Article

\title{
Dissipation and Migration of Pyrethroids in Auricularia polytricha Mont. from Cultivation to Postharvest Processing and Dietary Risk
}

\author{
Jin-Jing Xiao ${ }^{1,2,+}$, Jin-Sheng Duan ${ }^{3,+}$, Yan-Can Wu ${ }^{1,4}$, Yan-Hong Shi ${ }^{1,2}$, Qing-Kui Fang ${ }^{1,2}$, \\ Min Liao ${ }^{1,2}$, Ri-Mao Hua ${ }^{2}$ and Hai-Qun Cao ${ }^{1,2, * \text { (D) }}$ \\ 1 School of Plant Protection, Anhui Agricultural University, Hefei 230036, Anhui, China; \\ xiaojj187012@163.com (J.-J.X.); wuyancan1989@163.com (Y.-C.W.); shiyh@ahau.edu.cn (Y.-H.S.); \\ qkfang@163.com (Q.-K.F.); liaomin3119@126.com (M.L.) \\ 2 Provincial Key Laboratory for Agri-Food Safety, Anhui Agricultural University, Hefei 230036, Anhui, China; \\ rimaohua@126.com \\ 3 Institute of Plant Protection and Agro-Product Safety, Anhui Academy of Agricultural Sciences, \\ Hefei 230031, Anhui, China; djszbzas@126.com \\ 4 Hefei Testing and Inspection Center for Agricultural Products Quality of Anhui Province, \\ Hefei 230091, Anhui, China \\ * Correspondence: haiquncao@163.com; Tel.: +86-657-85730 \\ + These authors contributed equally to this work.
}

Received: 15 March 2018; Accepted: 28 March 2018; Published: 29 March 2018

\begin{abstract}
In order to ensure raw consumption safety the dissipation behavior, migration, postharvest processing, and dietary risk assessment of five pyrethroids in mushroom (Auricularia polytricha Mont.) cultivated under Chinese greenhouse-field conditions. Half-lives $\left(t_{1 / 2}\right)$ of pyrethroids in fruiting body and substrate samples were 3.10-5.26 and 17.46-40.06 d, respectively. Fenpropathrin dissipated rapidly in fruiting bodies ( $\left.t_{1 / 2} 3.10 \mathrm{~d}\right)$; bifenthrin had the longest $t_{1 / 2}$. At harvest, pyrethroid residues in A. polytricha (except fenpropathrin) were above the respective maximum residue limits (MRLs). Some migration of lambda-cyhalothrin was observed in the substrate-fruit body system. In postharvest-processing, sun-drying and soaking reduced pyrethroid residues by $25-83 \%$. We therefore recommend that consumers soak these mushrooms in $0.5 \% \mathrm{NaHCO}_{3}$ at $50{ }^{\circ} \mathrm{C}$ for $90 \mathrm{~min}$. Pyrethroids exhibit a particularly low $\mathrm{PF}$ value of $0.08-0.13 \%$, resulting in a negligible exposure risk upon mushroom consumption. This study provides guidance for the safe application of pyrethroids to edible fungi, and for the establishment of MRLs in mushrooms to reduce pesticide exposure in humans.
\end{abstract}

Keywords: mushroom; pyrethroids; residue behavior; migration; processing factors

\section{Introduction}

With a delicate flavor and texture, as well as a high content of trace minerals, Auricularia polytricha (Mont.) Sacc., also known as wood ear, is one of the most popular edible mushrooms. It has a characteristic flavor and several known biological activities, including antioxidant, antitumor, anti-dementia, and hypocholesterolemic effects [1]. This has led to expansion of the global edible fungi market [2]. China in particular is the world's largest producer and exporter of mushrooms, with an annual production output of around 50 million tons.

To meet increasing demand, the artificial cultivation of A. polytricha has expanded year on year, however, it is susceptible to a variety of insect infestations. The use of pesticides for combating insect pests and diseases in mushroom production has no doubt enhanced the production and 
quality of the products, but their indiscriminate use has led to the accumulation of pesticide residues, potentially harmful to humans and the environment [3,4]. In addition, sawdust is the main substrate for the cultivation of this mushroom, and is frequently reused, causing problematic residues in the substrate. Although not registered for this purpose in China, pyrethroids are used as insecticides for mushrooms by the majority of cultivators, causing exporting issues due to international restrictions. According to our survey, A. polytricha has been studied extensively for its artificial production, physiological properties, and nutritional value. However, little information is available on the behavior of pyrethroids in A. polytricha under cultivation conditions, especially in the migration and accumulation of pyrethroids in substrate-fruit body systems. Consequently, a thorough analysis of residue changes of pyrethroids in A. polytricha during cultivation is necessary.

The postharvest process, especially drying, is essential for preserving mushrooms, as fresh mushrooms have a high moisture content which causes perishablilty and microbial decomposition [5]. Numerous studies have demonstrated that food processing technology can contribute to pesticide dissipation [6,7]. The processing factor (PF) is the ratio of residue levels in processed products and their corresponding raw products, playing an important role in recommending maximum residue limits (MRLs) for processed products [8,9]. Moreover, MRLs are often only available for raw commodities. However, there are very few data concerning the behavior of pyrethroid residues in A. polytricha during postharvest processing. Accordingly, comprehensive knowledge of the fate of pyrethroids in the dry-storage-soak process is necessary to properly evaluate the human exposure from these pesticides.

The present work was designed to study the behavior of pyrethroids in mushrooms and their migration into the substrate-mushroom system. To investigate whether processing of the cultivated A. polytricha influences the levels of pyrethroids in the fruiting bodies, we also performed a series of experiments using various autoclave, storage, and drying conditions and soaking procedures. We also investigate the PFs during the postharvest dry-storage-soak process. This study may be helpful for establishing a rationale for pyrethroids MRLs in A. polytricha and provide relevant and useful data on the proper and safe use of pyrethroids.

\section{Results and Discussion}

\subsection{Method Validation}

Method validation was evaluated using selectivity, linearity, accuracy, and sensitivity. The selectivity was verified by comparison of the chromatograms obtained from fortified A. polytricha and substrates with those of blank samples. No interfering peaks were observed at the retention times of the tested analytes. Satisfactory linearity obtained with the squared correlation coefficients $\left(r^{2}\right)>0.999$ for the five pesticides analyzed by GC-ECD ranged from 0.005 to $1.0 \mathrm{mg} \cdot \mathrm{kg}^{-1}$. Accuracy data were provided by recovery tests conducted in quintuplicate using the fortified blank samples at three fortification levels. Satisfactory accuracy was achieved with a recovery of 76.04-103.09\% for dried A. polytricha, 81.68-96.39\% for fresh A. polytricha, and 82.66-102.83\% for the substrate (Table 1), respectively, which were within the ranges expected for residue analysis. Relative Standard Deviations (RSDs) $<10 \%$ for all pesticides demonstrated that the method is considered reliable enough for the routine analysis of the pesticide residues in this study. The sensitivity of the method was expressed in terms limits of detection (LODs), which were 0.50-1.60, 0.53-1.61, and $0.50-1.63 \mu \mathrm{g} \cdot \mathrm{kg}^{-1}$ for dried A. polytricha, A. polytricha, and substrate, respectively. The LODs of the five pyrethroids, considered as the concentration that produced a signal-to-noise ratio of 10 , ranged from 1.61 to $5.37 \mu \mathrm{g} \cdot \mathrm{kg}^{-1}$ for all matrixes. This demonstrated that LODs and LOQs were also sufficiently reliable for detecting the likely concentrations of the incurred residues during processing. 
Table 1. Recoveries (\%) and relative standard deviations (RSDs) for the five pyrethroids in A. polytricha and substrate samples at three spiking levels $(n=5)$.

\begin{tabular}{|c|c|c|c|c|c|c|c|c|c|c|c|}
\hline \multirow[b]{2}{*}{ Pesticides } & \multirow{2}{*}{$\begin{array}{l}\text { Fortified Level } \\
\left(\mathrm{mg} \cdot \mathrm{kg}^{-1}\right)\end{array}$} & \multicolumn{3}{|c|}{ Dried Mushroom } & \multicolumn{3}{|c|}{ Fresh Mushroom } & \multirow{2}{*}{$\begin{array}{l}\text { Fortified Level } \\
\quad\left(\mathrm{mg}^{-} \mathrm{kg}^{-1}\right)\end{array}$} & \multicolumn{3}{|c|}{ Substrate } \\
\hline & & $\begin{array}{c}\text { Average } \\
\text { Recovery }(\%)^{a}\end{array}$ & $\operatorname{RSD}(\%)^{b}$ & $\begin{array}{l}\mathrm{LQD} / \mathrm{LOQ} \\
\left(\mu \mathrm{g} \cdot \mathrm{kg}^{-1}\right)\end{array}$ & $\begin{array}{c}\text { Average } \\
\text { Recovery (\%) }\end{array}$ & RSD (\%) & $\begin{array}{l}\mathrm{LQD} / \mathrm{LOQ} \\
\left(\mu \mathrm{g} \cdot \mathrm{kg}^{-1}\right)\end{array}$ & & $\begin{array}{c}\text { Average } \\
\text { Recovery }(\%)\end{array}$ & RSD (\%) & $\begin{array}{l}\mathrm{LQD} / \mathrm{LOQ} \\
\left(\mu \mathrm{g} \cdot \mathrm{kg}^{-1}\right)\end{array}$ \\
\hline \multirow{3}{*}{ Bifenthrin } & 0.005 & $82.51 \pm 3.65^{c}$ & 3.99 & \multirow{3}{*}{$0.91 / 2.93$} & $95.02 \pm 5.74$ & 2.82 & \multirow{3}{*}{$0.86 / 2.87$} & 0.01 & $82.66 \pm 4.01$ & 2.58 & \multirow{3}{*}{$0.85 / 2.44$} \\
\hline & 0.05 & $76.89 \pm 2.54$ & 1.76 & & $90.42 \pm 4.52$ & 3.64 & & 0.1 & $93.93 \pm 4.15$ & 4.33 & \\
\hline & 0.5 & $83.56 \pm 4.12$ & 0.49 & & $81.68 \pm 3.25$ & 2.30 & & 1 & $88.52 \pm 3.87$ & 2.76 & \\
\hline \multirow{3}{*}{ Fenpropathrin } & 0.005 & $103.09 \pm 5.31$ & 2.16 & \multirow{3}{*}{$0.75 / 2.61$} & $94.71 \pm 3.34$ & 3.89 & \multirow{3}{*}{$0.79 / 2.64$} & 0.01 & $101.02 \pm 3.65$ & 1.67 & \multirow{3}{*}{$0.66 / 2.55$} \\
\hline & 0.05 & $80.44 \pm 4.33$ & 2.78 & & $90.60 \pm 4.26$ & 4.35 & & 0.1 & $93.22 \pm 3.77$ & 2.00 & \\
\hline & 0.5 & $82.66 \pm 3.87$ & 0.95 & & $85.30 \pm 3.39$ & 3.45 & & 1 & $87.93 \pm 2.96$ & 2.19 & \\
\hline \multirow{3}{*}{ Lambda-cyhalothrin } & 0.005 & $80.12 \pm 3.26$ & 1.72 & \multirow{3}{*}{$0.50 / 1.62$} & $85.96 \pm 3.46$ & 2.92 & \multirow{3}{*}{$0.53 / 1.77$} & 0.01 & $101.01 \pm 3.82$ & 2.49 & \multirow{3}{*}{$0.50 / 1.61$} \\
\hline & 0.05 & $76.04 \pm 2.57$ & 1.01 & & $93.24 \pm 4.55$ & 3.73 & & 0.1 & $96.74 \pm 3.54$ & 3.73 & \\
\hline & 0.5 & $90.13 \pm 4.57$ & 1.71 & & $96.39 \pm 4.12$ & 1.87 & & 1 & $87.07 \pm 2.99$ & 2.21 & \\
\hline \multirow{3}{*}{$\beta$-cypermethrin } & 0.005 & $98.63 \pm 5.44$ & 3.71 & \multirow{3}{*}{$1.60 / 5.34$} & $84.73 \pm 1.41$ & 4.30 & \multirow{3}{*}{$1.61 / 5.34$} & 0.01 & $102.83 \pm 5.54$ & 2.87 & \multirow{3}{*}{$1.63 / 5.37$} \\
\hline & 0.05 & $98.13 \pm 4.75$ & 2.31 & & $87.16 \pm 3.25$ & 3.26 & & 0.1 & $94.22 \pm 4.93$ & 1.11 & \\
\hline & 0.5 & $82.67 \pm 3.52$ & 0.61 & & $89.61 \pm 5.75$ & 2.35 & & 1 & $87.07 \pm 4.43$ & 2.45 & \\
\hline \multirow{3}{*}{ Deltamethrin } & 0.005 & $93.57 \pm 5.11$ & 2.26 & \multirow{3}{*}{$1.39 / 4.68$} & $90.49 \pm 3.76$ & 3.62 & \multirow{3}{*}{$1.42 / 4.73$} & 0.01 & $101.47 \pm 5.86$ & 4.99 & \multirow{3}{*}{$1.30 / 4.11$} \\
\hline & 0.05 & $81.96 \pm 3.57$ & 2.70 & & $86.52 \pm 3.13$ & 1.93 & & 0.1 & $96.53 \pm 4.37$ & 3.63 & \\
\hline & 0.5 & $80.13 \pm 2.54$ & 0.87 & & $92.08 \pm 4.84$ & 5.36 & & 1 & $84.88 \pm 2.58$ & 2.55 & \\
\hline
\end{tabular}

${ }^{\mathrm{a}}$ Five replicate extractions were performed for each treatment; ${ }^{\mathrm{b}}$ Relative standard deviation for reproducibility in $\%$; ${ }^{\mathrm{c}}$ Standard deviation. 


\subsection{Dissipation of Pyrethroid Residues in Substrate and Fruiting Bodies}

Kinetic dissipation was carried out to investigate if the substrate could pollute the environment or future crops. The dissipation curves of pyrethroids in the substrate after sterilization are shown in Figure 1a. The degradation trends of pyrethroids in the substrate followed first order kinetics, and their initial mean deposits ranged from $1.60-13.70 \mathrm{mg} \cdot \mathrm{kg}^{-1}$ (Table S1) with half-lives $\left(t_{1 / 2}\right)$ of 17.46-40.06 d. Fan et al. (2013) [10] reported that the half-lives of five pyrethroids in a growing medium of pleurotus ostreatus were $25.48-54.59 \mathrm{~d}$. Variability in degradation rate was observed among different types of samples, further proof that the crop characteristics affect the persistence of the pesticide. A sharp decrease was observed for the majority of pyrethroid residues $21 \mathrm{~d}$ after application, except for $\beta$-cypermethrin ( $14 \mathrm{~d}$ ). At the end of the sampling period ( $100 \mathrm{~d}$ after application), more than $85 \%$ of residues in pyrethroids in all testing sites had been degraded, except for bifenthrin $(77.05 \%)$. Bifenthrin may exhibit a longer half-life due to the absorption intensity of sawdust [11]. From the above, it is proposed that pyrethroids are fairly persistent in the substrate, and this warrants further study.
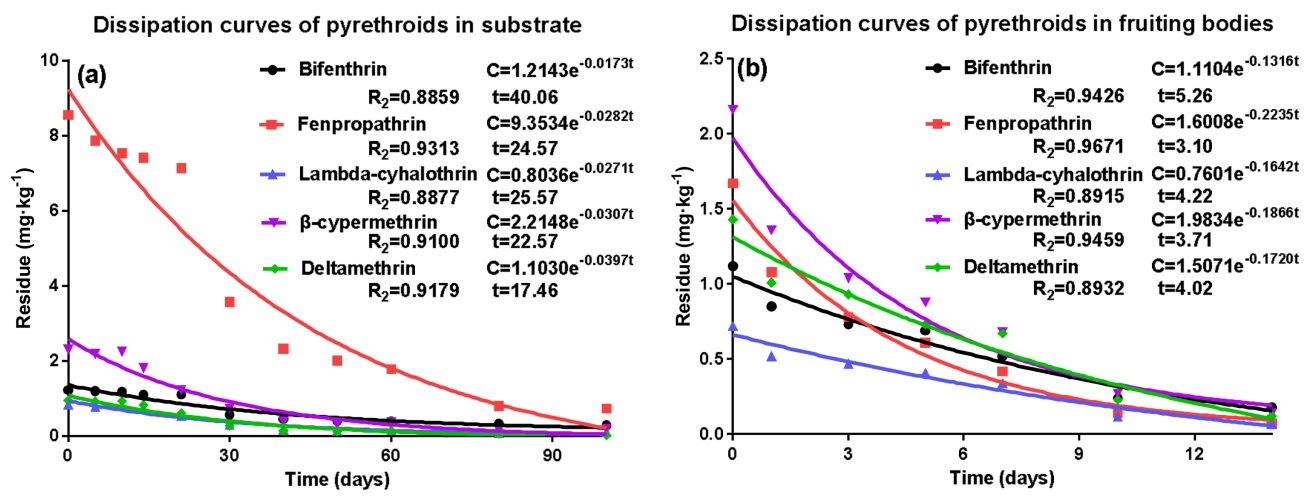

Figure 1. The dissipation curve of the five pyrethroid residues in the substrate (a) and fruiting body of $A$. polytricha $(\mathbf{b})$. Percentage digestion represent the percentage reduction of residues. Results are reported as mean \pm standard error (S.D.) (calculated from three independent experiments).

At the applied dosage of 1.5 times the recommended dosage, the initial residues in fruiting bodies were $1.12 \mathrm{mg} \cdot \mathrm{kg}^{-1}$ for bifenthrin, $1.67 \mathrm{mg} \cdot \mathrm{kg}^{-1}$ for fenpropathrin, $0.72 \mathrm{mg} \cdot \mathrm{kg}^{-1}$ for lambda-cyhalothrin, $2.16 \mathrm{mg} \cdot \mathrm{kg}^{-1} \beta$-cypermethrin, and $1.43 \mathrm{mg} \cdot \mathrm{kg}^{-1}$ for deltamethrin (Table S2). After $10 \mathrm{~d}, 80 \%$ of pyrethroids had degraded, and fenpropathrin and lambda-cyhalothrin levels in fruiting bodies were less than $0.07 \mathrm{mg} \cdot \mathrm{kg}^{-1} 14 \mathrm{~d}$ after application. The degradation trends of pyrethroids in fruiting bodies also followed first order kinetics (Figure $1 \mathrm{~b}$ ). The $t_{1 / 2}$ values of pyrethroids in fruiting bodies ranged from 3.10-5.26 d, demonstrating a faster degradation than that in the substrate.

Several factors, including environmental factors (light, moisture, and $\mathrm{pH}$ ), the crop characteristics, and physical and chemical properties of the pesticide (water solubility and volatility), have played a fundamental role in affecting pesticide persistence in crops [12]. A. polytricha was mainly cultivated in greenhouse. In this paper, the differences in $t_{1 / 2}$ could be raised by growth dilution factor and the type of plants, but less so by environmental factors.

\subsection{Terminal Residues of Pyrethroids in A. polytricha}

The terminal residue levels of five pyrethroids in A. polytricha could be detected after the last application at the recommended dose and the 1.5 times dose (Table 2). The results indicated that at the lower dosage of pyrethroids, the terminal residues ranged from $0.06-0.94 \mathrm{mg} \cdot \mathrm{kg}^{-1}$ in A. polytricha. At the high dosage, the five pyrethroid residues ranged from $0.11-1.59 \mathrm{mg} \cdot \mathrm{kg}^{-1}$, suggesting that the dosage played an important role on the residue. The harvest intervals after application also affected the residue of pyrethroids in A. polytricha. As harvest intervals increased, the residues 
declined considerably, for example, over $50 \%$ reduction of $\beta$-cypermethrin was observed in that collected after 3-5 d of application at the high dosage. It is expected that the highest residues are found at the shortest pre-harvest intervals. The residues of the five pyrethroids in A. polytricha also increased with an increase in application times, but the differences in the residues were not significant at the two experimental sites.

Table 2. Final residues of the five pyrethroids in A. polytricha $(n=3)$.

\begin{tabular}{|c|c|c|c|c|c|}
\hline \multirow{2}{*}{ Pesticides } & \multirow{2}{*}{$\begin{array}{l}\text { Application Dosage } \\
\text { (ai. }^{a} \mathrm{~g} / \mathrm{m}^{2} \text { ) }\end{array}$} & \multirow{2}{*}{ Spray Times } & \multicolumn{3}{|c|}{ Days after Application (Mean \pm SD $^{b}$ ) } \\
\hline & & & 3 & 5 & 7 \\
\hline \multirow{4}{*}{ Bifenthrin } & \multirow{2}{*}{1.25} & 1 & $0.49 \pm 0.06$ & $0.21 \pm 0.01$ & $0.11 \pm 0.02$ \\
\hline & & 2 & $0.56 \pm 0.02$ & $0.29 \pm 0.04$ & $0.21 \pm 0.01$ \\
\hline & \multirow{2}{*}{$0.83^{\mathrm{c}}$} & 1 & $0.64 \pm 0.10$ & $0.22 \pm 0.03$ & $0.16 \pm 0.02$ \\
\hline & & 2 & $077 \pm 0.05$ & $0.34 \pm 0.05$ & $0.28 \pm 0.03$ \\
\hline \multirow{4}{*}{ Fenpropathrin } & \multirow{2}{*}{1.25} & 1 & $0.71 \pm 0.04$ & $0.33 \pm 0.02$ & $0.09 \pm 0.04$ \\
\hline & & 2 & $0.79 \pm 0.05$ & $0.42 \pm 0.08$ & $0.21 \pm 0.01$ \\
\hline & \multirow{2}{*}{0.83} & 1 & $0.96 \pm 0.12$ & $0.28 \pm 0.01$ & $0.17 \pm 0.02$ \\
\hline & & 2 & $1.12 \pm 0.09$ & $0.51 \pm 0.06$ & $0.37 \pm 0.01$ \\
\hline \multirow{4}{*}{ Lambda-cyhalothrin } & \multirow{2}{*}{1.25} & 1 & $0.39 \pm 0.02$ & $0.14 \pm 0.03$ & $0.06 \pm 0.02$ \\
\hline & & 2 & $0.44 \pm 0.04$ & $0.19 \pm 0.06$ & $0.11 \pm 0.01$ \\
\hline & \multirow{2}{*}{0.83} & 1 & $0.53 \pm 0.05$ & $0.14 \pm 0.02$ & $0.11 \pm 0.05$ \\
\hline & & 2 & $0.63 \pm 0.06$ & $0.24 \pm 0.01$ & $0.16 \pm 0.03$ \\
\hline \multirow{4}{*}{$\beta$-cypermethrin } & \multirow{2}{*}{1.25} & 1 & $0.94 \pm 0.02$ & $0.37 \pm 0.03$ & $0.15 \pm 0.01$ \\
\hline & & 2 & $1.06 \pm 0.01$ & $0.51 \pm 0.05$ & $0.27 \pm 0.01$ \\
\hline & \multirow{2}{*}{0.83} & 1 & $1.29 \pm 0.17$ & $0.35 \pm 0.04$ & $0.22 \pm 0.02$ \\
\hline & & 2 & $1.59 \pm 0.06$ & $0.67 \pm 0.04$ & $0.33 \pm 0.04$ \\
\hline \multirow{4}{*}{ Deltamethrin } & \multirow{2}{*}{1.25} & 1 & $0.84 \pm 0.10$ & $0.30 \pm 0.05$ & $0.13 \pm 0.03$ \\
\hline & & 2 & $0.96 \pm 0.02$ & $0.43 \pm 0.02$ & $0.25 \pm 0.01$ \\
\hline & \multirow{2}{*}{0.83} & 1 & $1.14 \pm 0.03$ & $0.31 \pm 0.04$ & $0.23 \pm 0.04$ \\
\hline & & 2 & $1.34 \pm 0.10$ & $0.56 \pm 0.01$ & $0.31 \pm 0.06$ \\
\hline
\end{tabular}

${ }^{a}$ ai., active ingredient; ${ }^{b}$ Standard deviation; ${ }^{c}$ Not registered in China for use on edible fungi. The recommended dosages of these compounds referred to pesticides for use in other plants.

Regardless of the dosage or spray times, $7 \mathrm{~d}$ after spraying, the final residues of pyrethroids in all of the A. polytricha mushroom samples (except fenpropathrin which was sprayed once, collecting after $7 \mathrm{~d}$ of application at a lower dosage) were above the respective MRL $\left(0.05 \mathrm{mg} \cdot \mathrm{kg}^{-1}\right.$ of bifenthrin and $\beta$-cypermethrin, $0.1 \mathrm{mg} \cdot \mathrm{kg}^{-1}$ of fenpropathrin, $0.02 \mathrm{mg} \cdot \mathrm{kg}^{-1}$ of lambda-cyhalothrin, and $0.01 \mathrm{mg} \cdot \mathrm{kg}^{-1}$ of deltamethrin) established in the EU, Japan, or China (Table 2). Human exposure to pyrethroids may cause subacute or chronic toxicity like neurotoxicity, immunotoxicity, reproductive and developmental toxicity $[13,14]$. This study shows that significant pesticide residue was detected in A. polytricha under the designed experiment, outside the acceptable residual level limits. It is thus evident that the residues of pyrethroids in fresh A. polytricha pose a potential health risk and this should be an area of continued focus. Considering the high terminal residue in A. polytricha, the dosage of application and harvest interval should be controlled in order to make it safer, and this needs further research.

\subsection{Migration of Pyrethroids in the Substrate-Mushroom System}

Substrate for cultivation of A. polytricha was prepared using straw, sawdust and cottonseed hull. These ingredients allow the migration of pyrethroids into the fruiting body during its growth process, and expose the edible fungi to potential pesticide residues. In this paper, the migration of five pyrethroids into $A$. polytricha fruiting bodies from substrate was investigated over a 15-d period (Table S3). 
Lambda-cyhalothrin was the only pesticide standard found in the fruiting bodies to show moderate recovery. The highest migration efficiency of lambda-cyhalothrin into fruiting bodies was observed in the first harvest $(95 \mathrm{~d})$ ), followed by a notable drop, which reflects the saturation points of the matrices. Migration into fruiting bodies was significantly affected by the initial concentration of the lambda-cyhalothrin, similar to previous findings in the paddy by Barik et al. [15]. The sawdust may be derived from polluted tree and substrate is frequently reused. However, this behavior means that the pyrethroids have a weak migration capacity, which improves the safety and quality of A. polytricha. Considering the accumulation of lambda-cyhalothrin in fruiting bodies, which was over $0.02 \mathrm{mg} \cdot \mathrm{kg}^{-1}$, we do not recommend the use of lambda-cyhalothrin in mushrooms. This is the first time that lambda-cyhalothrin has been shown to migrate into edible fungi.

\subsection{Effects of Processing}

\subsubsection{Effects of Autoclaving on the Residue Dissipation Behaviors}

The substrate used in A. polytricha cultivation is frequently sterilized using high-pressure-steam before use. Moist heat can accelerate the decomposition of pyrethroids, and the dissipation was beyond $20 \%[16,17]$. In order to determine the effect of autoclaving on the removal of pyrethroids in the substrate, fortified samples were prepared for pesticide analysis prior to, and immediately after, sterilization in an autoclave (Figure 2). Significant differences between results prior to, and after, sterilization was observed after autoclaving. Furthermore, our survey demonstrated that autoclaving significantly increased the levels of pyrethroids, with a range of $37.59-57.65 \%$, consistent with that found in the earlier work [16]. The water involved in autoclaving could entrain pesticide molecules causing co-distillation, while heat promotes the degradation and evaporation of pesticides during the process [18]. Variations in degradation may be due to the chemical nature of the individual pesticides, including vapor pressure, water solubility, volatility, and tendency to bind to a matrix. Hence, it can be concluded that lambda-cyhalothrin is, in contrast to other pesticides, considerably more unstable during autoclaving.

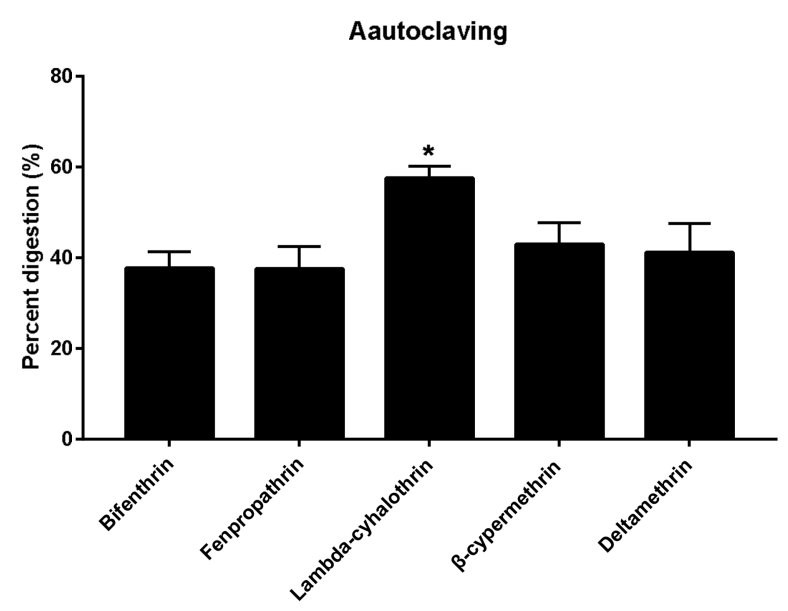

Figure 2. Effects of autoclaving process on residue levels of the five pyrethroids in A. polytricha. Results are reported as mean \pm standard error (S.D.) (calculated from three independent experiments). Percentage digestion represent the percentage reduction of residues. The asterisks indicate significant differences in the percentage digestion among the five pyrethroids or different parameters in processed A. polytricha. ( ${ }^{*} p$ value $\left.<0.05\right)$.

\subsubsection{Effects of Two Drying Methods on the Residue Dissipation Behaviors}

Fresh A. polytricha contain porphyrins, which are potentially hazardous to consumers [19]. The drying process can significantly decrease the levels of porphyrins. Thus, consumers usually 
purchase the cultivated mushroom as a processed product. We investigated the influence of the two drying methods, sun- and oven-drying, on the residues of the pyrethroids at the low (Figure 3a) and high (Figure 3b) level. The results showed that the two drying methods have an effect on the degradation of the five insecticides used on A. polytricha. The percentage digestion of the pyrethroids ranged from 9.30-51.25\%, with bifenthrin and deltamethrin showing the most degradation, followed by $\beta$-cypermethrin, whereas fenpropathrin and lambda-cyhalothrin showed comparatively less. Compared to oven-drying, sun-drying played a more significant role in promoting the degradation of the five pesticides, e.g., the amount of bifenthrin digestion was $43.61-51.25 \%$ and $23.76-24.82 \%$ for sun-drying and oven-drying treatments, respectively. In addition, the percentage digestion of the pyrethroids changed, but not statistically significantly, between the high- and low-dosage treatments after processing. These results suggest that in addition to a higher temperature, photolysis may also be a decisive factor that contributes to pesticide degradation during the drying process [20,21]. Interestingly, the drying process caused evaporation of water from products (around 70\%), whereas the concentration of pesticides in final samples increased 2-3 times. A similar phenomenon has also been observed in other products, e.g., chili peppers [22], suggesting that the moisture content should be considered during the drying. At present, the MRL of edible fungi accepted in China does not distinguish between the fresh or dried products, so it is necessary to further subdivide.
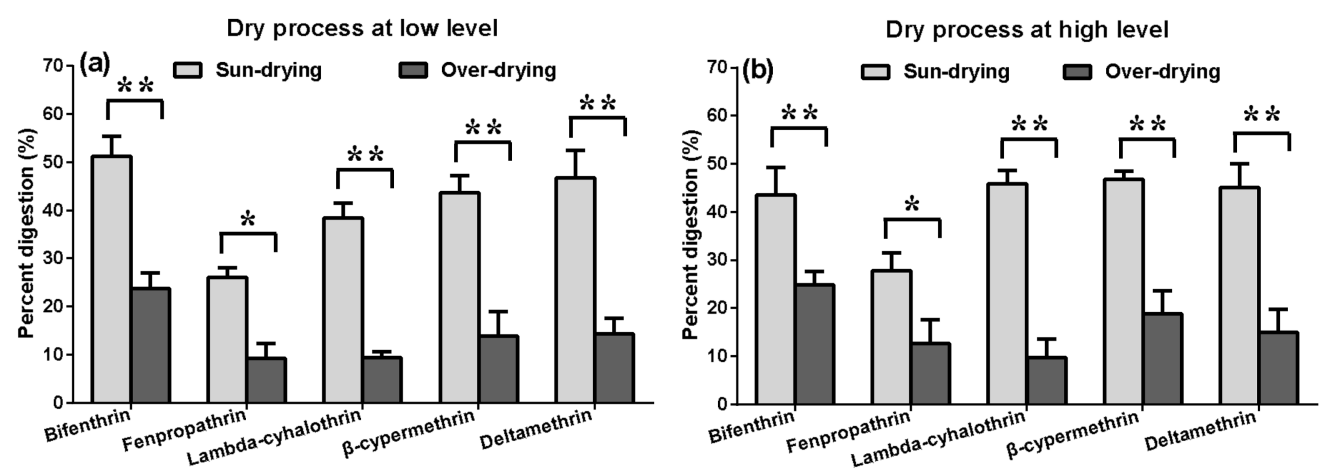

Figure 3. Effects of sun- and oven-drying at low (a) and high level (b). Results are reported as mean \pm standard error (S.D.) (calculated from three independent experiments). Percentage digestion represent the percentage reduction of residues. The asterisks indicate significant differences in the percentage digestion among the five pyrethroids or different parameters in processed A. polytricha. ( $p$ value $<0.05$ and ${ }^{* *} p$ value $\left.<0.01\right)$.

\subsubsection{Effects of Storage on the Residue Dissipation Behaviors}

When bought fresh and stored for a shorter time, mushrooms are usually kept in the refrigerator. To store for longer times, mushrooms are either frozen or dried. We followed the percentage digestion of the pyrethroids during storage at low temperature $\left(0-5{ }^{\circ} \mathrm{C}\right.$, Figure $\left.4 \mathrm{a}\right)$ and room temperature $\left(25^{\circ} \mathrm{C}\right.$, Figure $4 \mathrm{~b}$ ). Our survey showed that the percentage digestion of the pyrethroids was related to the storage time. For fresh A. polytricha, a small percentage digestion (around 15-20\%) after $5 \mathrm{~d}$ treatment was observed during the low-temperature storage. However, no significant differences were observed with increasing time. For room-temperature storage, the mean loss of pyrethroids was 32-40\% after $150 \mathrm{~d}$ treatment, which indicates that the degradation of pyrethroids is slow at room temperature, especially from 60-120 d. At the same time, the percentage digestion at room-temperature storage was slower than that at low-temperature storage. The result is in contrast to the previous studies with other pesticide residues in agricultural commodities. This be justified by storing A. polytricha in a dry, air-tight container, in a cool dark place [23]. 

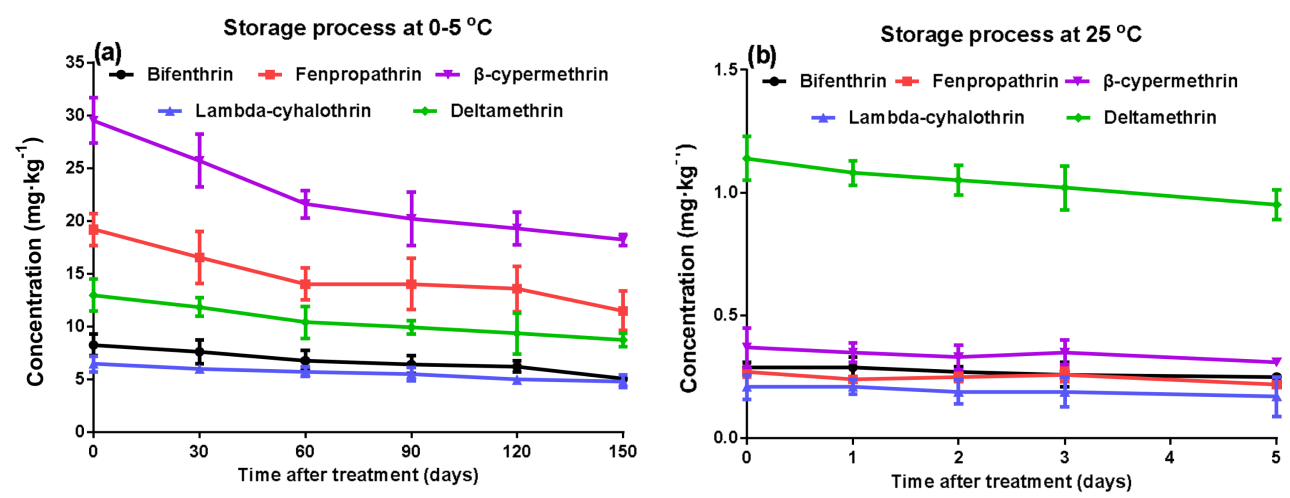

Figure 4. Effects of storage of fresh A. polytricha at low temperature $\left(0-5{ }^{\circ} \mathrm{C}\right)(\mathbf{a})$ and dried A. polytricha at room temperature $\left(25^{\circ} \mathrm{C}\right)(\mathbf{b})$. Results are reported as mean \pm standard error (S.D.) (calculated from three independent experiments).

\subsubsection{Effects of Soaking on the Residue Dissipation Behaviors}

Soaking with water is an essential before household cooking, to wash and to make the A. polytricha absorb enough water, to restore the dried mushrooms to a similar state as fresh ones. As shown in Figure $5 \mathrm{a}-\mathrm{c}$, soaking had a significant effect on the reduction of pyrethroids, with a mean $60 \%$ decrease. The loss increases with increasing temperature (Figure 5a), intervals (Figure 5b), and times (Figure 5c). The average removal percentage of the three methods showed no statistically significant differences, whereas a moderate difference was observed between pesticides. Bifenthrin showed a comparatively lower loss of the residues during the various soaking procedures.
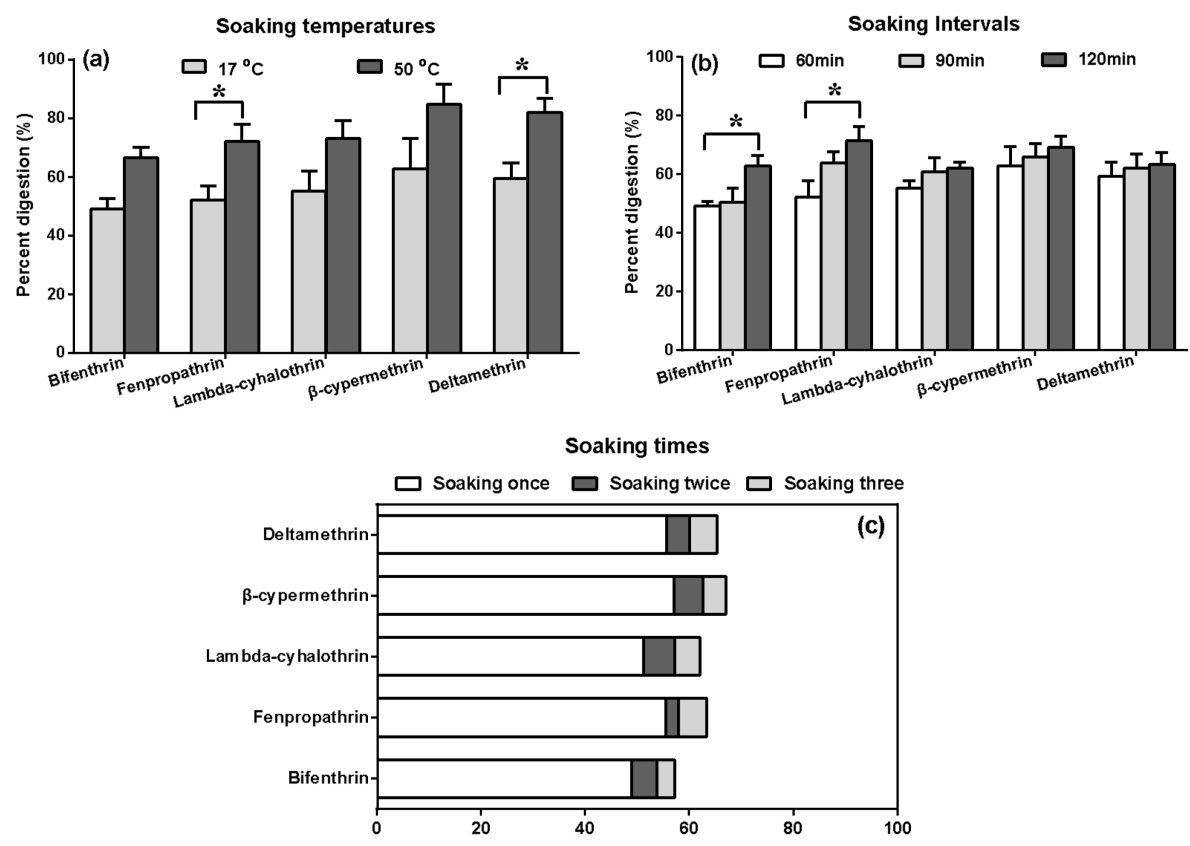

Figure 5. Effects of soaking temperatures (a), soaking intervals (b), and soaking times (c). Results are reported as mean \pm standard error (S.D.) (calculated from three independent experiments). Percentage digestion represent the percentage reduction of residues. The asterisks indicate significant differences in the percentage digestion among the five pyrethroids or different parameters in processed A. polytricha. (* $p$ value $<0.05)$.

The differences in results might be related to the different physico-chemical properties of the tested pyrethroids, including water-octanol partition coefficients $\left(\log \mathrm{K}_{\mathrm{ow}}\right)$ and water solubility $[24,25]$. 
Moreover, washing has been found to reduce pesticide residues that are loosely attached to the surface [26]. The skin of A. polytricha is mainly pectin. Pyrethroids had no effects on the systemic properties [27], but were mainly present on the surface of the fruiting bodies. The percentage removal of these pesticides through soaking indicates that soaking is an effective way to remove these four pesticides.

In a further report, pesticide residues and removal percentage were affected with various solutions, e.g., sodium chloride $(\mathrm{NaCl})$, acetic acid $\left(\mathrm{C}_{2} \mathrm{H}_{4} \mathrm{O}_{2}\right)$, or sodium bicarbonate $\left(\mathrm{NaHCO}_{3}\right)$ [28]. As shown in Figure 6, after soaking with different solutions, the mean losses of bifenthrin, fenpropathrin, lambda-cyhalothrin, $\beta$-cypermethrin, and deltamethrin were 20.73-66.25\%, $35.06-82.98 \%, 19.08-71.57 \%, 20.73-71.86 \%, 30.91-76.34 \%$, respectively. The most efficient removal from $A$. polytricha was observed using $0.5 \% \mathrm{NaHCO}_{3}$, while soaking with $\mathrm{NaCl}$ and $\mathrm{C}_{2} \mathrm{H}_{4} \mathrm{O}_{2}$ were less efficient in comparison. With a few exceptions, the residue of the five pesticides decreased by increasing the concentration of $\mathrm{NaCl}$ (Figure 6a), in contrast to the results with $\mathrm{C}_{2} \mathrm{H}_{4} \mathrm{O}_{2}$ (Figure $6 \mathrm{~b}$ ) and $\mathrm{NaHCO}_{3}$ (Figure 6c). This tendency might be related to the saturation of the pyrethroids, with $\mathrm{NaCl}$ enhancing the saturation, and thus causing lower transfer to the infusion. The average removal percentage of pyrethroids by the $\mathrm{NaCl}$ solution is lower than that of tap water, except at the $0.1 \%$ concentration, whereas removal of pyrethroids by $\mathrm{NaHCO}_{3}$ was more effective than tap water at high concentrations, especially for fenpropathrin. This may be due to the alkaline nature of the solution (pyrethroid pesticides are stable in acidic and neutral conditions but aqueous hydrolysis occurs under alkaline conditions) can enhance the solubility, and the release from the A. polytricha [29]. A similar process was studied by Wang et al. [30] who found that soaking in a dilute alkaline solution ( $\mathrm{pH}$ 9.0) only eliminated $37.82 \%$ of the residues of the $\beta$-cypermethrin in contaminated vegetables, further demonstrating that pesticides have different behavior in different materials.
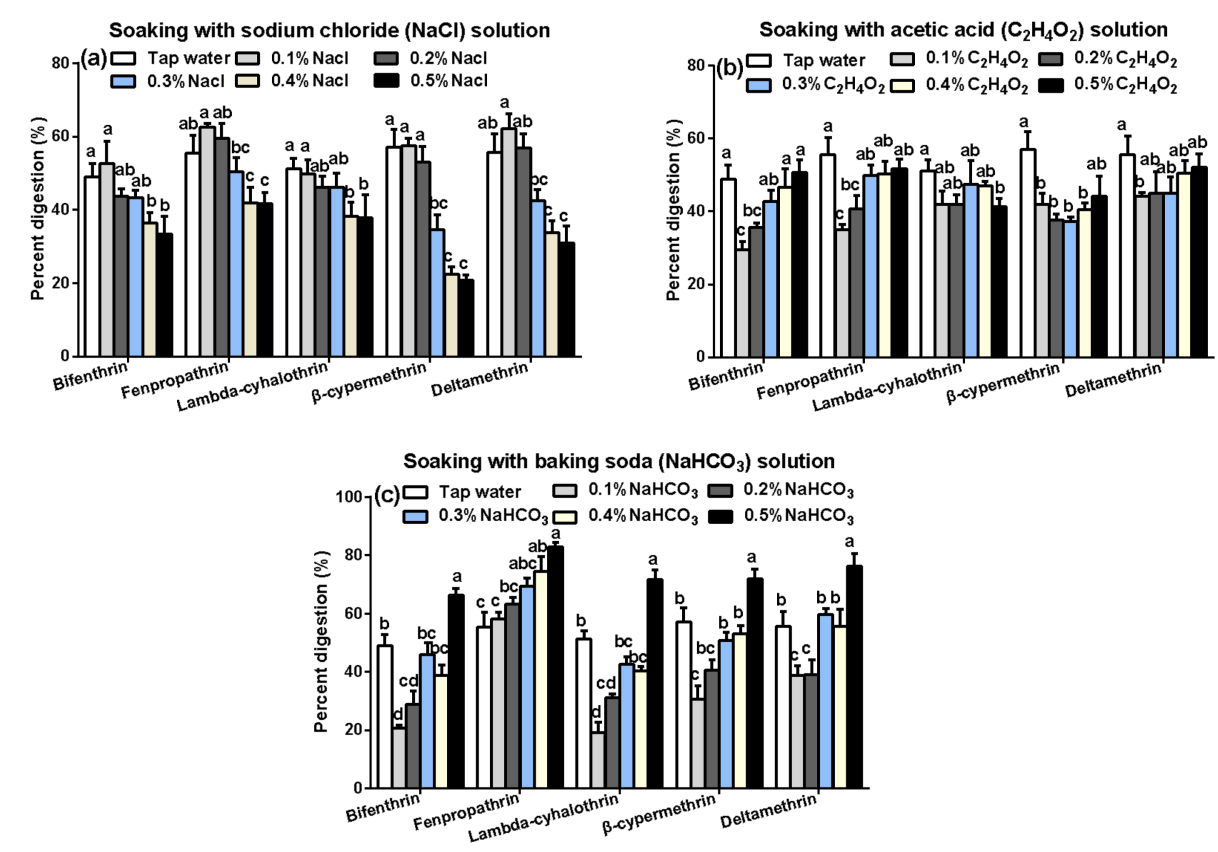

Figure 6. Effects of sodium chloride $(\mathrm{NaCl})(\mathbf{a})$, acetic acid $\left(\mathrm{C}_{2} \mathrm{H}_{4} \mathrm{O}_{2}\right)(\mathbf{b})$, and sodium bicarbonate $\left(\mathrm{NaHCO}_{3}\right)$ (c) solutions on the removal percent of the five pyrethroid residues in A. polytricha during household-soaking. Percentage digestion represent the percentage reduction of residues. Different minor case letters at the top of the columns indicate significant differences at a $p$ value of 0.05 .

The results suggested that sun-drying and soaking were very effective procedures for reducing pesticide residues in the fruiting bodies. Moreover, we recommend processing the mushroom with 
sun-drying and soaking at $50{ }^{\circ} \mathrm{C}$ for 90 min with $0.5 \% \mathrm{NaHCO}_{3}(\mathrm{pH} 8.35)$, as suggested by the present findings.

\subsection{Processing Factors and Dietary Risk}

We know that different food processing technologies will lead to different residue levels, and the disposition of the residues in various processed products [31]. The PFs lay an important role in performing a risk assessment for a pesticide under a specific treatment in specific commodity $[9,32]$. The calculated PFs for the five insecticides after processing are shown in Table 3. Results show that all PFs were $<1$, indicating that their residual ratios are decreased during the entire process. During the soaking process, the PFs of the five pesticides were all less than 0.34 , indicating that this process considerably reduced their residues in the A. polytricha. Moreover, the PFs of the overall process for bifenthrin, fenpropathrin, lambda-cyhalothrin, $\beta$-cypermethrin, and deltamethrin were $0.10,0.08,0.13$, 0.10 , and 0.09 , respectively, demonstrating that the whole process can significantly reduce the residue of pesticides in A. polytricha postharvest processing.

Table 3. Processing factors (PFs) for the five pyrethroids after different processes $(n=3)$.

\begin{tabular}{cccccc}
\hline Process & Bifenthrin & Fenpropathrin & Lambda-Cyhalothrin & $\beta$-Cypermethrin & Deltamethrin \\
\hline Drying & 0.49 & 0.74 & 0.62 & 0.56 & 0.53 \\
Storage & 0.61 & 0.60 & 0.75 & 0.62 & 0.67 \\
Soaking & 0.34 & 0.17 & 0.28 & 0.28 & 0.24 \\
Overall process & 0.10 & 0.08 & 0.13 & 0.10 & 0.09 \\
\hline
\end{tabular}

\section{Materials and Methods}

\subsection{Chemicals and Samples}

A. polytricha and substrate were purchased from a local market as the main materials. None of the studied pyrethroids were detected in the samples. Pyrethroid analytical standards (bifenthrin (98.0\%), fenpropathrin (99.2\%), lambda-cyhalothrin (99.2\%), $\beta$-cypermethrin (99.2\%), and deltamethrin $(98.4 \%))$ were purchased from the National Pesticide Quality Supervision and Inspection Center (Beijing, China). Standard stock solutions of the pyrethroids were prepared in $n$-hexane. Subsequently, matrix-matched standard solutions were prepared by adding the appropriate stock solution using blank extracts of $A$. polytricha and substrate samples. All solutions were stored at $4{ }^{\circ} \mathrm{C}$ until use. The substances obtained through commercial sources included $25 \mathrm{~g} \cdot \mathrm{L}^{-1}$ bifenthrin emulsifiable concentrate (EC) (Jiangsu Yangnong Chemical Group Co., Ltd., Yangzhou, Jiangsu, China), $200 \mathrm{~g} \cdot \mathrm{L}^{-1}$ fenpropathrin EC (Tianjin Xingguang Chemical Co., Ltd., Tianjin, China), $25 \mathrm{~g} \cdot \mathrm{L}^{-1}$ lambda-cyhalothrin EC (Zhejiang Shijia Technology Co. Ltd., Huzhou, Zhejiang, China), $25 \mathrm{~g} \cdot \mathrm{L}^{-1} \beta$-cypermethrin EC (Qingdao Han Sheng Bio Polytron Technologies Inc., Qingdao, China), and $25 \mathrm{~g} \cdot \mathrm{L}^{-1}$ deltamethrin EC (Jiangsu Yangnong Chemical Group Co., Ltd.).

\subsection{Cultivation Conditions, Pest Surveys, and Field Trials}

Trials were conducted in cultures of the commercial strains 120 of A. polytricha in mushroom growing rooms using a plastic bag cultivation method [33]. The greenhouse had three trials, 90 cubic meters $\left(\mathrm{m}^{3}\right)$ in each trial. Of which, two trials for the field dissipation behavior study were carried out by different application treatments (premixing and spraying) during the cultivation of A. polytricha, and one trial was conducted for the study of the processing process.

Before cultivation, each polyethylene bag (height $38 \mathrm{~cm}$, diameter $10 \mathrm{~cm}$ ) was filled with $2.5 \mathrm{~kg}$ of substrate ( $74 \%$ of sawdust, $25 \%$ of cottonseed hull, $1-2.5 \%$ of lime) and sterilized at $100{ }^{\circ} \mathrm{C}$ for 14-16 h. After cooling, the substrate was inoculated with $9 \mathrm{~cm}^{2}$ mycelial agar discs. The spawn was incubated at $25^{\circ} \mathrm{C}$ under dark conditions until the substrate was fully colonized. Then, a temperature of $25 \pm 3{ }^{\circ} \mathrm{C}$ and a relative humidity of $65-75 \%$ were maintained throughout cultivation. 


\subsubsection{Pesticides for Trials of Premixing Treatment}

Three separate field trials were conducted in an experimental greenhouse according to the guidelines on pesticide residue trials. Multi-mixing different pesticides (1:750 $(w / w$, single dosage) and 1:500 (w/w, 1.5 times dosage) for the ratio of the pesticide to the substrate, to ensure an ample amount of pesticide residues) was premixed with the non-sterilized or sterilized substrates before inoculation of the A. polytricha. The substrates without addition of any pesticide were used as control. A total of 12 substrates were used for each treatment. The prepared substrates premixed with pesticides were sealed into polyethylene bags and then the A. polytricha were inoculated to the substrates and cultivated conventionallyas mentioned previously. Approximately $200.0 \mathrm{~g}$ of non-sterilized and sterilized substrate (single dosage) was harvested at $0,5,10,14,21,30,40,50,60,80$, and $100 \mathrm{~d}$ to analyze the effect of autoclaving on the removal of pyrethroids in substrate and their dissipation behavior. Another $1.0 \mathrm{~g}$ of sterilized substrates diluted to a single and 1.5 times dosage were harvested at the first $(95 \mathrm{~d})$, second $(110 \mathrm{~d})$, and third harvest (125 d) to investigate the migration of pyrethroids in the substrate-mushroom system. The 12 samples of the same batch were taken and their content was mixed and then separated into triplicate for analysis.

\subsubsection{Pesticides for Trials of Spraying Treatment}

The spraying treatment was designed as residue dynamic trials, consisting of 6 treatment plots and one control plot without application of the pesticide. Each plot consisted of an area of $10 \mathrm{~m}^{2}$ (approximately 12 of polyethylene bag). The recommended dosage $\left(0.83\right.$ ai. $\left.\mathrm{g} / \mathrm{m}^{2}\right)$ and 1.5 times the recommended dosage $\left(1.25 \mathrm{ai} . \mathrm{g} / \mathrm{m}^{2}\right)$ used in vegetables was applied. The pesticides were diluted with $0.25 \mathrm{~L}$ of water and sprayed in each plot $\left(10 \mathrm{~m}^{2}\right)$ when the fruiting bodies of A. polytricha had grown to maturity (average height of $2 \mathrm{~cm}$ ). Subsequently, about $200.0 \mathrm{~g}$ of A. polytricha were picked at $0(2 \mathrm{~h}), 1,3,5,7,10,14 \mathrm{~d}$ after spraying.

To study the terminal residue, another two dosage levels, 0.83 ai. $\mathrm{g} / \mathrm{m}^{2}$ (recommended dosage) and 1.25 ai. $\mathrm{g} / \mathrm{m}^{2}$ was sprayed in another two treatment plots. Each dosage application was sprayed once or twice with an interval of $7 \mathrm{~d}$. Subsamples were collected at pre-harvest intervals of 3, 5, and 7 $\mathrm{d}$ after the last spray. Samples of the same batch were taken and their content was mixed and then separated into triplicate for analysis.

\subsection{Postharvest Processing and Home-Soaking Experiments}

In general, the processing procedures of A. polytricha include three stages; storage, drying, and soaking. In this study, pyrethroids were applied at 0.83 and 4.15 ai. $\mathrm{g} / \mathrm{m}^{2}$ (5 times the recommended dosage) to ensure an ample amount of pesticide residues. Then, subsamples were collected at $2 \mathrm{~h}$ to determine the variation of pesticide residue during the processing procedure. The detailed processing procedures are as follows.

Drying: for sun-drying, $1.0 \mathrm{~kg}$ of the fortified fresh samples were spread over a $1 \mathrm{~m}^{2}$ of area (open air, $35-40{ }^{\circ} \mathrm{C}$ ) until samples were fully dry. For oven-drying, the samples were placed in an oven at $50{ }^{\circ} \mathrm{C}$ for $6 \mathrm{~h}$ (until the weight no longer changed).

Storage: fresh A. polytricha stored at $0-5{ }^{\circ} \mathrm{C}$ in the refrigerator (Shanghai Kendall cold storage company, Shanghai, China) for $0,1,2,3$, and $5 \mathrm{~d}$; dried samples stored at room temperature in a dry environment for $1,30,60,90,120$, and $150 \mathrm{~d}$.

Soaking: to investigate the effect of water temperature, $100 \mathrm{~g}$ of dried A. polytricha was soaked in water ( $2 \mathrm{~L}$ ) at either $17^{\circ} \mathrm{C}$ or $50^{\circ} \mathrm{C}$ for $60 \mathrm{~min}$. The effect of soaking intervals was examined at intervals of 60,90 , and $120 \mathrm{~min}$ in the same manner. To investigate the effect of soaking time, $100 \mathrm{~g}$ of sample was immersed in $2 \mathrm{~L}$ of water at room temperature for $10 \mathrm{~min}$. Subsequently, the liquid portion was decanted and collected as the first soaking. Then, another $2 \mathrm{~L}$ of water was poured into the original utensil to soak the residual samples and to obtain a second soaking. A third infusion was also obtained 
by the same process. In addition, samples were immersed in water $(2 \mathrm{~L})$ with varying levels $(0.1 \%$, $0.2 \%, 0.3 \%, 0.4 \%$, and $0.5 \%$ ) of baking soda, vinegar, and salt at room temperature for $90 \mathrm{~min}$.

\subsection{Gas Chromatography (GC) Analysis}

The spiked substrate $(5.0 \mathrm{~g})$ or fresh or dried mushroom $(10.0 \mathrm{~g})$ was exactly weighed into a $50 \mathrm{~mL}$ centrifuge tube, and extracted and cleaned according to our previously reported method [34]. The elute was concentrated to dryness and reconstituted in $5.0 \mathrm{~mL}$ of $n$-hexane for GC with electron capture detection (ECD).

A 2010 Plus Network GC system (Shimadzu, Kyoto, Japan) equipped with a ${ }^{63} \mathrm{Ni}$ ECD and a Rtx-5 capillary column ( $30 \mathrm{~m} \times 25 \mu \mathrm{m} \times 2.5 \mu \mathrm{m}$ film thickness) was used for pesticide analysis. The detector and injection temperatures were maintained at $300^{\circ} \mathrm{C}$ and $250{ }^{\circ} \mathrm{C}$, respectively. The GC settings were as follows: the initial oven temperature was held at $60^{\circ} \mathrm{C}$ for $1 \mathrm{~min}$, ramped at $30^{\circ} \mathrm{C} / \mathrm{min}$ to $180^{\circ} \mathrm{C}$ and $5{ }^{\circ} \mathrm{C} / \mathrm{min}$ to $250{ }^{\circ} \mathrm{C}$ for $5 \mathrm{~min}$, and then ramped at $3{ }^{\circ} \mathrm{C} / \mathrm{min}$ to $280^{\circ} \mathrm{C}$ for $1 \mathrm{~min}$. The carrier gas was nitrogen $\left(99.999 \%\right.$ ) at a flow rate of $1.5 \mathrm{~mL} \cdot \mathrm{min}^{-1}$, and the sample injection volume was $2 \mu \mathrm{L}$ in the splitless mode.

\subsection{Statistical Analysis}

Data are expressed as the mean \pm S.D. Statistical analysis for each parameter was performed using analysis of variance (ANOVA) followed by Tukey's test [35]. All figures were drawn using the software Origin Pro 9.0 (Origin Lab Corporation, Northampton, MA, USA). Differences among means were considered statistically significant at a $p$ value of 0.05 . The PFs are calculated and considered by the Joint FAO/WHO Meeting on Pesticide Residues (JMPR) [36]:

$$
\mathrm{PF}=\frac{\text { The residue levels of processed commodities }}{\text { The residue levels of the raw commodities }}
$$

PF values $<1$ (=reduction factor) indicate a decrease of the residue in the processed commodity, while values $>1$ (=concentration factor) indicate a concentration effect of the processing steps [37].

\section{Conclusions}

In this study, changes in bifenthrin, fenpropathrin, lambda-cyhalothrin, $\beta$-cypermethrin, and deltamethrin residue levels from cultivation to postharvest processing (storage and drying) and home soaking were studied. Many factors such as the chemical properties of the particular pesticide, processing procedure, etc. could affect the removal of pesticide residues. The soaking process was found to be the most effective for the reduction of pesticide residues. The present study provides residue data which may be useful for establishing MRL and assessing the amount of pyrethroid residues in mushrooms under Chinese field conditions. Moreover, the present findings suggest that a need for implementation of these safety intervals before harvesting and marketing such edible fungi.

Supplementary Materials: The following are available online, Table S1: Pyrethroid residues in the substrate at different time intervals $(n=3)$, Table S2: Pyrethroid residues in fruiting bodies at different time intervals $(n=3)$, Table S3: Migration and accumulation of pyrethroids in the substrate-mushroom system $(n=3)$.

Acknowledgments: This work was supported by the Anhui Natural Science Foundation (1508085MC50) and Natural Science Key Research Project of Colleges and Universities in Anhui Province, China (KJ2016A038).

Author Contributions: H.-Q.C., J.-J.X. and J.-S.D. conceived and designed the experiments; J.-J.X. and Y.-C.W. performed the experiments; J.-J.X., Y.-H.S. and Q.-K.F. analyzed the data; M.L. and R.-M.H. contributed reagents / materials/analysis tools; H.-Q.C. and J.-J.X. wrote the paper.

Conflicts of Interest: The authors declare no conflict of interest. 


\section{References}

1. Liang, C.-H.; Wu, C.-Y.; Lu, P.-L.; Kuo, Y.-C.; Liang, Z.-C. Biological efficiency and nutritional value of the culinary-medicinal mushroom auricularia cultivated on a sawdust basal substrate supplement with different proportions of grass plants. Saudi J. Biol. Sci. 2016. [CrossRef]

2. Kalac, P. Trace element contents in European species of wild growing edible mushrooms: A review for the period 2000-2009. Food Chem. 2010, 122, 2-15. [CrossRef]

3. Cao, X.; Liu, S.; Yang, X.; Liu, Z.; Liu, L. A modified quechers sample preparation method for simultaneous determination of 62 pesticide residues in edible fungi using gas chromatography-triple quadrupole mass spectrometry. Food Anal. Methods 2016, 9, 263-274. [CrossRef]

4. Wieland, M.; Hacker, K.; Bauer, N.; Schüle, E.; Wauschkuhn, C.; Roux, D.; Scherbaum, E.; Anastassiades, M. Pesticide Residues in Fresh and Dried Mushrooms on the German Market. Chemisches und Veterinaruntersuchungsamt, Stuttgart, Baden-Wü Rttemberg, Germany. Available online: http:/ / cvusa.xnuntersuchungsmter-bw-nzb.de/pdf/MushroomPM036.pdf (accessed on 20 June 2010).

5. Li, Y.J.; Ishikawa, Y.; Satake, T.; Kitazawa, H.; Qiu, X.L.; Rungchang, S. Effect of active modified atmosphere packaging with different initial gas compositions on nutritional compounds of shiitake mushrooms (Lentinus edodes). Postharvest Biol. Technol. 2014, 92, 107-113. [CrossRef]

6. Ramezani, M.K.; Shahriari, D. Dissipation behaviour, processing factors and risk assessment for metalaxyl in greenhouse-grown cucumber. Pest Manag. Sci. 2015, 71, 579-583. [CrossRef] [PubMed]

7. Fernandez-Cruz, M.L.; Barreda, M.; Villarroya, M.; Peruga, A.; Llanos, S.; Garcia-Baudin, J.M. Captan and fenitrothion dissipation in field-treated cauliflowers and effect of household processing. Pest Manag. Sci. 2006, 62, 637-645. [CrossRef] [PubMed]

8. Caldas, E.D.; Tressou, J.; Boon, P.E. Dietary exposure of Brazilian consumers to dithiocarbamate pesticides-A probabilistic approach. Food Chem. Toxicol. 2006, 44, 1562-1571. [CrossRef] [PubMed]

9. Zhao, L.W.; Liu, F.M.; Wu, L.M.; Xue, X.F.; Hou, F. Fate of triadimefon and its metabolite triadimenol in jujube samples during jujube wine and vinegar processing. Food Control 2017, 73, 468-473. [CrossRef]

10. Fan, Z.-C.; Tang, J.; Cao, H.-Q.; Wu, X.-W.; Hua, R.-M.; Tang, F.; Yue, Y.-D. Degradation kinetics of 5 pyrethroid pesticide residues in pleurotus ostreatus and growing medium. Food Sci. 2013, 11, 009.

11. Domingues, V.; Alves, A.; Cabral, M.; Delerue-Matos, C. Sorption behaviour of bifenthrin on cork. J. Chromatogr A 2005, 1069, 127-132. [CrossRef] [PubMed]

12. Liao, M.; Shi, Y.H.; Cao, H.Q.; Hua, R.M.; Tang, F.; Wu, X.W.; Tang, J. Dissipation behavior of octachlorodipropyl ether residues during tea planting and brewing process. Environ. Monit. Assess. 2016, 188, 551. [CrossRef] [PubMed]

13. Hughes, M.F.; Ross, D.G.; Starr, J.M.; Scollon, E.J.; Wolansky, M.J.; Crofton, K.M.; DeVito, M.J. Environmentally relevant pyrethroid mixtures: A study on the correlation of blood and brain concentrations of a mixture of pyrethroid insecticides to motor activity in the rat. Toxicology 2016, 359, 19-28. [CrossRef] [PubMed]

14. Miyamoto, J.; Kaneko, H.; Tsuji, R.; Okuno, Y. Pyrethroids, nerve poisons: How their risks to human health should be assessed. Toxicol. Lett. 1995, 82, 933-940. [CrossRef]

15. Barik, S.R.; Ganguly, P.; Kunda, S.K.; Kole, R.K.; Bhattacharyya, A. Persistence behaviour of thiamethoxam and lambda cyhalothrin in transplanted paddy. Bull. Environ. Contam. Toxicol. 2010, 85, 419-422. [CrossRef] [PubMed]

16. Dordevic, T.M.; Siler-Marinkovic, S.S.; Durovic, R.D.; Dimitrijevic-Brankovic, S.I.; Umiljendic, J.S.G. Stability of the pyrethroid pesticide bifenthrin in milled wheat during thermal processing, yeast and lactic acid fermentation, and storage. J. Sci. Food Agric. 2013, 93, 3377-3383. [CrossRef] [PubMed]

17. Wang, Y.P.; Sun, Y.; Gao, Y.; Xu, B.; Wu, Q.; Zhang, H.Q.; Song, D.Q. Determination of five pyrethroids in tea drinks by dispersive solid phase extraction with polyaniline-coated magnetic particles. Talanta 2014, 119, 268-275. [CrossRef] [PubMed]

18. Cabras, P.; Angioni, A.; Garau, L.; Melis, M.; Pirisi, F.M.; Cabitza, F.; Pala, M. Pesticide residues in raisin processing. J. Agric. Food Chem. 1998, 46, 2309-2311. [CrossRef]

19. Ouzouni, P.K.; Veltsistas, P.G.; Paleologos, E.K.; Riganakos, K.A. Determination of metal content in wild edible mushroom species from regions of Greece. J. Food Compos. Anal. 2007, 20, 480-486. [CrossRef] 
20. Frangos, P.; Shen, W.H.; Wang, H.J.; Li, X.; Yu, G.; Deng, S.B.; Huang, J.; Wang, B.; Wang, Y.J. Improvement of the degradation of pesticide deethylatrazine by combining UV photolysis with electrochemical generation of hydrogen peroxide. Chem. Eng. J. 2016, 291, 215-224. [CrossRef]

21. Clark, T.; Watkins, D.A.M.; Weerasinghe, D.K. Photolysis of fluotrimazole. Pestic. Sci. 1983, 14, 449-452. [CrossRef]

22. Noh, H.H.; Kim, D.K.; Lee, E.Y.; Chang, M.I.; Im, M.H.; Lee, Y.D.; Kyung, K.S. Effects of oven drying on pesticide residues in field-grown chili peppers. J. Korean Soc. Appl. Biol. 2015, 58, 97-104. [CrossRef]

23. Kujawski, M.W.; Namiesnik, J. Challenges in preparing honey samples for chromatographic determination of contaminants and trace residues. Trac-Trend Anal. Chem. 2008, 27, 785-793. [CrossRef]

24. Chen, H.P.; Pan, M.L.; Pan, R.; Zhang, M.L.; Liu, X.; Lu, C.Y. Transfer rates of 19 typical pesticides and the relationship with their physicochemical property. J. Agric. Food Chem. 2015, 63, 723-730. [CrossRef] [PubMed]

25. British Crop Protection Council. The Pesticide Manual: A World Compendium, 11th ed.; Tomlin, C.D.S., Ed.; British Crop Protection Council: Alton, UK, 1997.

26. Kong, Z.Q.; Dong, F.S.; Xu, J.; Liu, X.G.; Zhang, C.P.; Li, J.; Li, Y.B.; Chen, X.; Shan, W.L.; Zheng, Y.Q. Determination of difenoconazole residue in tomato during home canning by UPLC-MS/MS. Food Control 2012, 23, 542-546. [CrossRef]

27. Matsuo, N.; Miyamoto, J. Development of Synthetic Pyrethroids with Emphasis on Stereochemical Aspects; ACS Publications: Washington, DC, USA, 1997.

28. Radwan, M.A.; Abu-Elamayem, M.M.; Shiboob, M.H.; Abdel-Aal, A. Residual behaviour of profenofos on some field-grown vegetables and its removal using various washing solutions and household processing. Food Chem. Toxicol. 2005, 43, 553-557. [CrossRef] [PubMed]

29. Hand, L.H.; Kuet, S.F.; Lane, M.C.G.; Maund, S.J.; Warinton, J.S.; Hill, I.R. Influences of aquatic plants on the fate of the pyrethroid insecticide lambida-cyhalothrin in aquatic environments. Environ. Toxicol. Chem. 2001, 20, 1740-1745. [PubMed]

30. Wang, C.-F.; Chen, F.; Wei, H.; You, Y.; Xiu, D.-M. Removing methods for $\beta$-cypermethrin residue in contaminated vegetables. J. Agro-Environ. Sci. 2005, 24, 1018-1021.

31. Peng, W.; Zhao, L.W.; Liu, F.M.; Xue, J.Y.; Li, H.C.; Shi, K.W. Effect of paste processing on residue levels of imidacloprid, pyraclostrobin, azoxystrobin and fipronil in winter jujube. Food Addit. Contam. A 2014, 31, 1562-1567. [CrossRef] [PubMed]

32. Reiler, E.; Jors, E.; Baelum, J.; Huici, O.; Caero, M.M.A.; Cedergreen, N. The influence of tomato processing on residues of organochlorine and organophosphate insecticides and their associated dietary risk. Sci. Total Environ. 2015, 527, 262-269. [CrossRef] [PubMed]

33. Phan, C.W.; Sabaratnam, V. Potential uses of spent mushroom substrate and its associated lignocellulosic enzymes. Appl. Microbiol. Biotechnol. 2012, 96, 863-873. [CrossRef] [PubMed]

34. Shi, Y.-H.; Xiao, J.-J.; Feng, R.-P.; Liu, Y.-Y.; Liao, M.; Wu, X.-W.; Hua, R.-M.; Cao, H.-Q. In-vitro bioaccessibility of five pyrethroids after human ingestion and the corresponding gastrointestinal digestion parameters: A contribution for human exposure assessments. Chemosphere 2017, 182, 517-524. [CrossRef] [PubMed]

35. Ghosh, M.N.; Sharma, D. Power of tukey's test for non-additivity. J. R. Stat. Soc. Ser. B 1963, 25, $213-219$.

36. World Health Organization (WHO); Food and Agriculture Organization of the United Nations (FAO). Updating, the Principles and Methods of Risk Assessment Mrls for Pesticidas and Veterinary Drugs; FAO: Rome, Italy, 2006.

37. Timme, G.; Walz-Tylla, B. Effects of food preparation and processing on pesticide residues in commodities of plant origin. In Pesticide Residues Food Drinking Water; John Wiley \& Sons: Hoboken, NJ, USA, 2004; pp. 121-148.

(C) 2018 by the authors. Licensee MDPI, Basel, Switzerland. This article is an open access article distributed under the terms and conditions of the Creative Commons Attribution (CC BY) license (http://creativecommons.org/licenses/by/4.0/). 